\title{
Postdialysis blood pressure rise predicts long-term outcomes in chronic hemodialysis patients: a four- year prospective observational cohort study
}

\author{
Chih-Yu Yang ${ }^{1,2}$, Wu-Chang Yang ${ }^{1,2}$ and Yao-Ping Lin ${ }^{1,2^{*}}$
}

\begin{abstract}
Background: The blood pressure (BP) of a proportion of chronic hemodialysis (HD) patients rises after HD. We investigated the influence of postdialysis BP rise on long-term outcomes.

Methods: A total of 115 prevalent HD patients were enrolled. Because of the fluctuating nature of predialysis and postdialysis BP, systolic BP (SBP) and diastolic BP before and after HD were recorded from 25 consecutive HD sessions during a 2-month period. Patients were followed for 4 years or until death or withdrawal.

Results: Kaplan-Meier estimates revealed that patients with average postdialysis SBP rise of more than $5 \mathrm{mmHg}$ were at the highest risk of both cardiovascular and all-cause mortality as compared to those with an average postdialysis SBP change between -5 to $5 \mathrm{mmHg}$ and those with an average postdialysis SBP drop of more than 5 $\mathrm{mmHg}$. Furthermore, multivariate Cox regression analysis indicated that both postdialysis SBP rise of more than 5 $\mathrm{mmHg}(\mathrm{HR}, 3.925[95 \% \mathrm{Cl}, 1.410-10.846], p=0.008)$ and high cardiothoracic (CT) ratio of more than 50\% (HR, 7.560 [95\% Cl, 2.048-27.912], $p=0.002$ ) independently predicted all-cause mortality. We also found that patients with an average postdialysis SBP rise were associated with subclinical volume overload, as evidenced by the significantly higher $C T$ ratio $(p=0.008)$.

Conclusions: A postdialysis SBP rise in HD patients independently predicted 4-year cardiovascular and all-cause mortality. Considering postdialysis SBP rise was associated with higher $\mathrm{CT}$ ratio, intensive evaluation of cardiac and volume status should be performed in patients with postdialysis SBP rise.
\end{abstract}

Keywords: Postdialysis blood pressure, Systolic blood pressure, Cardiothoracic ratio, Hemodialysis, Mortality

\section{Background}

Due to oliguria or even anuria, most end-stage renal disease (ESRD) patients undergoing maintenance hemodialysis (HD) require ultrafiltration during HD in order to maintain a euvolemic status. Although the volumedependent component of hypertension may be corrected by fluid removal, a proportion of HD patients experience postdialysis BP rise. The underlying mechanisms of intradialytic hypertension are complex and have been considered to be caused by clinically silent fluid overload, activation of the renin-angiotensin axis, sympathetic overactivity, endothelial dysfunction, and sodium

\footnotetext{
*Correspondence: linyp@vghtpe.gov.tw

'Division of Nephrology, Department of Medicine, Taipei Veterans General

Hospital, No. 201, Section 2, Shih-Pai Road, Taipei 11217, Taiwan

Full list of author information is available at the end of the article
}

loading during HD [1-8]. Inrig et al. recently recognized its association with endothelial cell dysfunction, which was assessed by peripheral blood endothelial progenitor cells and ultrasonographic measurement of brachial artery flow-mediated vasodilation underlie the pathogenesis of intradialytic hypertension [9].

Cardiovascular disease is the leading cause of morbidity and mortality in ESRD [10]. Hypertension is highly prevalent in patients undergoing HD and contributes to the high cardiovascular morbidity and mortality in these patients [11]. Postdialysis BP goals should be below 130/ $80 \mathrm{mmHg}$ according to the National Kidney Foundation's Kidney Disease Outcomes Quality Initiative (KDOQI) recommendation [12]. Surprisingly, little attention had been paid on postdialysis hypertension until some recent studies showed its clinical significance
C Biomed Central

(c) 2012 Yang et al; licensee BioMed Central Ltd. This is an Open Access article distributed under the terms of the Creative Commons Attribution License (http://creativecommons.org/licenses/by/2.0), which permits unrestricted use, distribution, and reproduction in any medium, provided the original work is properly cited. 
using BP recordings from 3-6 HD sessions $[1,4,13]$. However, the predictive values of predialysis and postdialysis BP have been disputed due to its high variability nature [14-16], which could be overcome by increasing the number of BP recording times for more than 1 month $[17,18]$.

Although some studies have demonstrated the adverse impact of intradialytic hypertension on 2-year all-cause mortality $[1,4]$, the relationship between postdialysis hypertension and cardiovascular outcomes was unknown. We hypothesized that poor overall survival in such patients is related to volume overload that leading to future cardiovascular death. We also aimed to elucidate whether the adverse outcomes persist with higher follow-up. Therefore, we followed up our HD patients for more than 4 years and included cardiovascular mortality in patient outcomes as well.

\section{Methods}

\section{Study protocol and subjects}

From January 2006 to June 2010, we conducted a prospective observational cohort study at the Taipei Veterans General Hospital, a tertiary-care referral hospital. Each enrolled subject provided written informed consent, and this study was approved by the Institutional Review Board of Taipei Veterans General Hospital. All patients were at least 18 years of age, had ESRD, and had been on maintenance HD for at least 3 months. At study entry in 2006, we screened all prevalent HD patients in our unit $(n=178)$. We excluded recent adverse cardiovascular events or hospitalization within 3 months $(n=7)$, signs of current infection $(n=7)$, active autoimmune disease/collagen vascular disease $(n=1)$, advanced/severe liver disease $(n=2)$, patients received HD only twice weekly $(n=12)$, and patients who refused to provide consent $(n=34)$. Eventually, a total of 115 prevalent HD patients were enrolled.

At study entry, we recorded predialysis and postdialysis systolic BP (SBP) and diastolic BP (DBP) for 25 consecutive HD sessions during a 2 -month period. The demographic features and clinical parameters, including age, gender, duration of dialysis, body weight index, comorbidities, nutritional supplements, medications, serum biochemical data, and blood cell counts were obtained. Smoking status was defined as never (0), quit (1), or current smoker (2). Cardiothoracic (CT) ratios were obtained from postdialysis chest radiographs in a standing position (posterior-anterior view). The CT ratio was calculated by dividing the maximal transverse diameter of the cardiac silhoutte by the transverse inner diameter of the rib cage. It was interpreted by an independent radiologist and two independent nephrologists separately, and was then averaged from three data of each patient to reflect the volume status.

\section{Dialysis procedures}

HD was performed three times weekly (4 hours per session) using $1.8-\mathrm{m}_{2}$ surface area dialyzers with bicarbonate-based dialysates (sodium, $140 \mathrm{mEq} / \mathrm{L}[\mathrm{mmol} / \mathrm{L}]$; bicarbonate, $39 \mathrm{mEq} / \mathrm{L}[\mathrm{mmol} / \mathrm{L}]$; potassium, $2.0 \mathrm{mEq} / \mathrm{L}$ [mmol/L]; calcium, $3.0 \mathrm{mEq} / \mathrm{L}$; and magnesium 1.0 $\mathrm{mEq} / \mathrm{L}$ ). All patients were treated with recombinant human erythropoietin at an average dosage of 20,000 units monthly, with a target hematocrit level of $30-36 \%$.

\section{BP measurements}

Brachial artery BP was measured with the mercury sphygmomanometer in seated position. Predialysis BP was measured at the beginning of HD after 15 minutes of quiet rest. Postdialysis BP was measured at the end of HD 15 minutes after disconnecting from the dialysis circuit. Both predialysis and postdialysis BP were measured in the seated position. Mean arterial pressure (MAP) was calculated as $(\mathrm{SBP}+2 \times \mathrm{DBP}) / 3$. Pulse pressure (PP) was calculated from the SBP and DBP $(\mathrm{PP}=\mathrm{SBP}$ DBP). Postdialysis BP rise or drop was defined by the difference between postdialysis and predialysis BP values. The variability of postdialysis SBP alteration of each patient was also examined. We first calculated the percentage of postdialysis SBP alteration in each HD sessions as (postdialysis SBP - predialysis SBP)/predialysis SBP * $100 \%$. A total of 25 postdialysis SBP alteration percentages were obtained from each patient. We further calculated the standard deviation of these 25 data, which was defined as the variability of postdialysis SBP alteration of each patient. Ultrafiltration volume was defined as the amount of fluid removed within an HD session. All of the BP values and ultrafiltration volume were averaged from 25 consecutive HD sessions during a 2-month period.

\section{Laboratory measurements}

Blood samples were collected before the mid-week HD session. Samples were centrifuged within 1 hour of collection and then immediately sent to the central laboratory for analysis. Laboratory data were recorded as the average of 3 months' data. All measurements were determined in a single central laboratory.

\section{Clinical outcomes}

After baseline assessments, all patients were followed for 4 years or until death. Patients who received a kidney transplantation were censored at the time of transplantation. Clinical outcomes were death due to non-cardiovascular etiologies and cardiovascular diseases, including acute myocardial infarction, sudden cardiac arrest, fatal arrhythmia, cardiogenic shock, and stroke. For cardiovascular mortality, patients were also censored at the time of other causes of death. The causes of death were 
determined by the attending physicians who had no knowledge of patient grouping according to postdialysis BP alterations. In cases of death that did not occur in our hospital, family members were interviewed by telephone to ascertain the cause and time of death.

\section{Statistical analysis}

Chi-square analysis or Fisher's exact test was used for comparison of categorical variables as appropriate. Continuous variables were compared by analysis of variance (ANOVA), Student's $t$-test, or paired $t$-test as appropriate. Values of the continuous variables are presented as mean and standard deviation, unless otherwise specified. The Cox proportional hazards model was used to determine the significance of variables in predicting the primary end-point, including all-cause mortality and cardiovascular mortality. Variables associated with clinical outcomes in univariate Cox regression analysis with $p$ values less than 0.10 were used for multivariate Cox regression analysis. Kaplan-Meier analysis was used to assess the difference among patients with a postdialysis $\mathrm{BP}$ rise of more than $5 \mathrm{mmHg}$, those with a postdialysis SBP change between -5 to $5 \mathrm{mmHg}$, and those with a postdialysis BP drop of more than $5 \mathrm{mmHg}$ in reaching the primary end-point. This comparison was performed using the log-rank test. SPSS version 15.0 for Windows (SPSS Inc., Chicago, Illinois, USA) was used for all statistical analyses. All probabilities were two-tailed and a $p$ value of less than 0.05 was considered statistically significant.

\section{Results}

\section{Baseline characteristics of study subjects}

Table 1 shows the baseline characteristics of the 115 patients who were followed for 4 years. At enrollment, the mean age was 64 years, $45 \%$ of patients were male, and the mean duration on dialysis was 5.8 years. A total of 46 patients $(40 \%)$ had diabetes mellitus, 105 patients (91\%) had hypertension, 30 patients (26\%) had cardiovascular diseases, 5 patients (4\%) had a history of stroke, and 9 patients (8\%) had malignancy. BP before and after $\mathrm{HD}$ and ultrafiltration volume were averaged from 25 consecutive HD sessions during a 2-month period. We categorized our patients into 3 groups, including patients with an average postdialysis SBP rise of more than $5 \mathrm{mmHg}(n=39)$, those with an average postdialysis SBP change between -5 to $5 \mathrm{mmHg}(n=27)$, and those with an average postdialysis SBP drop of more than $5 \mathrm{mmHg}(n=49)$.

Compared to patients with an average postdialysis SBP change between -5 to $5 \mathrm{mmHg}$ and those with an average postdialysis SBP drop for more than $5 \mathrm{mmHg}$, those with an average postdialysis SBP rise of more than $5 \mathrm{mmHg}$ were more likely to be older $(p=0.007)$, have a higher percentage of antihypertensive agents usage $(p=0.025)$, lower hemoglobin level $(p=0.077)$, smaller ultrafiltration volume $(p=0.006)$, and higher CT ratio $(p=0.002)$.

Figure 1 shows the histogram of postdialysis SBP alterations of $2875 \mathrm{HD}$ sessions in 115 patients. Among all of the patients, the average SBP of 39 patients (33.9\%) rose more than $5 \mathrm{mmHg}$ after dialysis. In addition, the average MAP of 31 patients (27.0\%), DBP of 23 patients (20.0\%), and PP of 32 patients (27.8\%) rose more than $5 \mathrm{mmHg}$ after dialysis. Figure 2 shows the differences between predialysis and postdialysis BP in patients with an average postdialysis SBP rise of more than $5 \mathrm{mmHg}(n=39)$ and those with an average postdialysis SBP drop of more than $5 \mathrm{mmHg}(n=49)$. For patients with an average postdialysis BP for more than $5 \mathrm{mmHg}$, the average predialysis BPs were $138 \pm 17 \mathrm{mmHg}$ (range, 103 to $164 \mathrm{mmHg}$ ) for SBP, $96 \pm 10 \mathrm{mmHg}$ (range, 76 to $112 \mathrm{mmHg}$ ) for MAP, $75 \pm 7 \mathrm{mmHg}$ (range, 61 to 87 $\mathrm{mmHg}$ ) for DBP, and $63 \pm 12 \mathrm{mmHg}$ (range, 40 to 85 $\mathrm{mmHg}$ ) for PP. The average postdialysis BPs were $153 \pm 19$ $\mathrm{mmHg}$ (range, 109 to $182 \mathrm{mmHg}$ ) for SBP, $104 \pm 10$ $\mathrm{mmHg}$ (range, 81 to $119 \mathrm{mmHg}$ ) for MAP, $80 \pm 7 \mathrm{mmHg}$ (range, 67 to $96 \mathrm{mmHg}$ ) for DBP, and $73 \pm 15 \mathrm{mmHg}$ (range, 42 to $102 \mathrm{mmHg}$ ) for PP.

\section{Relationship between postdialysis BP rise and long-term clinical outcomes}

The mean follow-up time was $3.4 \pm 1.4$ years. By the censoring date, 40 patients (35\%) had died, of whom 18 (16\%) were related to cardiovascular etiologies. The causes of cardiovascular death were acute myocardial infarction (7 patients), sudden cardiac arrest suspected fatal arrhythmia (6 patients), critical aortic stenosis (3 patients), and stroke (2 patients). Among patients who died due to non-cardiovascular mortality, the causes of mortality were sepsis (16 patients), malignancy (4 patients), severe gastrointestinal bleeding (1 patient), and hollow organ perforation (1 patient). Seven patients were given kidney transplantations. Univariate Cox regression analysis indicated that patients with an average postdialysis SBP rise of more than $5 \mathrm{mmHg}$ were more likely to suffer from cardiovascular mortality (HR, 3.756 [95\% CI, 1.454-9.703], $p=0.006$ ) and all-cause mortality (HR, 2.382 [95\% CI, 1.280-4.434], $p=0.006$ ) than those without. However, the variability of postdialysis SBP alteration was not associated with all-cause mortality (HR, 0.949 [95\% CI, 0.872-1.033], $p=0.230$ ) or cardiovascular mortality (HR, 1.004 [95\% CI, 0.908-1.109], $p=0.945$ ).

\section{Postdialysis SBP rise was associated with both cardiovascular and all-cause mortality}

Kaplan-Meier estimates showed a significantly greater cardiovascular mortality rate for patients with an average postdialysis SBP rise of more than $5 \mathrm{mmHg}$ than for those with an average postdialysis SBP change between 
Table 1 Demographic characteristics of the study population

\begin{tabular}{|c|c|c|c|c|c|}
\hline Factor & All & $\begin{array}{l}\text { Patients with postdialytic } \\
\text { SBP rise }>5 \mathrm{mmHg}\end{array}$ & $\begin{array}{l}\text { Patients with postdialytic SBP } \\
\text { change between }-5 \text { to } 5 \mathrm{mmHg}\end{array}$ & $\begin{array}{l}\text { Patients with postdialytic } \\
\text { SBP drop }>5 \mathrm{mmHg}\end{array}$ & $p$ Value \\
\hline Patient number & 115 & 39 & 27 & 49 & \\
\hline Age (year) & $64.0 \pm 13.6$ & $68.6 \pm 11.5$ & $65.1 \pm 16.0$ & $59.6 \pm 12.6$ & $0.007^{*}$ \\
\hline Male gender (\%) & 45.2 & 41.0 & 33.3 & 55.1 & 0.153 \\
\hline $\begin{array}{l}\text { Dialysis duration } \\
\text { (year) }\end{array}$ & $5.8 \pm 5.3$ & $4.5 \pm 5.3$ & $6.8 \pm 6.1$ & $6.2 \pm 4.7$ & 0.180 \\
\hline $\begin{array}{l}\text { Body mass index } \\
\left(\mathrm{Kg} / \mathrm{m}^{2}\right)\end{array}$ & $22.0 \pm 3.5$ & $21.7 \pm 3.4$ & $21.9 \pm 3.6$ & $22.2 \pm 3.5$ & 0.840 \\
\hline Smoking index & $0.46 \pm 0.74$ & $0.46 \pm 0.79$ & $0.41 \pm 0.69$ & $0.49 \pm 0.74$ & 0.900 \\
\hline $\mathrm{Kt} / \mathrm{N}$ & $1.60 \pm 0.26$ & $1.61 \pm 0.22$ & $1.62 \pm 0.22$ & $1.59 \pm 0.31$ & 0.873 \\
\hline \multicolumn{6}{|l|}{ Comorbidities (\%) } \\
\hline $\begin{array}{l}\text { Diabetes mellitus } \\
(\%)\end{array}$ & 40.0 & 43.6 & 37.0 & 38.8 & 0.844 \\
\hline Hypertension (\%) & 91.3 & 89.7 & 92.6 & 91.8 & 1.000 \\
\hline $\begin{array}{l}\text { Cardiovascular } \\
\text { disease (\%) }\end{array}$ & 26.1 & 30.8 & 29.6 & 20.4 & 0.487 \\
\hline Prior stroke (\%) & 4.3 & 7.7 & 0.0 & 4.1 & 0.365 \\
\hline Malignancy (\%) & 7.8 & 15.4 & 3.7 & 4.1 & 0.136 \\
\hline \multicolumn{6}{|l|}{ Medications } \\
\hline $\begin{array}{l}\text { ACE inhibitor/ } \\
\text { ARB (\%) }\end{array}$ & 47.0 & 53.8 & 44.4 & 42.9 & 0.565 \\
\hline $\begin{array}{l}\text { Antihypertensive } \\
\text { agents (\%) }\end{array}$ & 79.1 & 89.7 & 85.2 & 67.3 & $0.025^{*}$ \\
\hline $\begin{array}{l}\text { Antiplatelet } \\
\text { agents (\%) }\end{array}$ & 33.0 & 41.0 & 33.3 & 26.5 & 0.356 \\
\hline Statins (\%) & 35.7 & 33.3 & 37.0 & 36.7 & 0.933 \\
\hline Fibrates (\%) & 7.0 & 10.3 & 3.7 & 6.1 & 0.719 \\
\hline Vitamin $D_{3}(\%)$ & 19.1 & 15.4 & 18.5 & 22.4 & 0.702 \\
\hline $\begin{array}{l}\text { Hepatitis B infection } \\
(\%)\end{array}$ & 7.8 & 7.7 & 0.0 & 12.2 & 0.172 \\
\hline $\begin{array}{l}\text { Hepatitis C infection } \\
(\%)\end{array}$ & 18.3 & 12.8 & 25.9 & 18.4 & 0.409 \\
\hline \multicolumn{6}{|l|}{ Laboratory data } \\
\hline Albumin $(\mathrm{g} / \mathrm{dL})$ & $4.1 \pm 0.3$ & $4.1 \pm 0.3$ & $4.2 \pm 0.3$ & $4.2 \pm 0.3$ & 0.224 \\
\hline $\begin{array}{l}\text { Total cholesterol } \\
(\mathrm{mg} / \mathrm{dL})\end{array}$ & $173.5 \pm 36.1$ & $175.4 \pm 35.0$ & $171.1 \pm 31.4$ & $173.4 \pm 39.9$ & 0.895 \\
\hline $\begin{array}{l}\text { Triglycerides } \\
\text { (mg/dL) }\end{array}$ & $182.9 \pm 125.2$ & $166.6 \pm 113.1$ & $190.8 \pm 145.1$ & $191.4 \pm 123.9$ & 0.614 \\
\hline $\begin{array}{l}\text { Sodium } \\
(\mathrm{mmol} / \mathrm{L})\end{array}$ & $139.8 \pm 2.9$ & $139.4 \pm 2.9$ & $139.9 \pm 3.5$ & $140.0 \pm 3.1$ & 0.693 \\
\hline $\begin{array}{l}\text { Chloride } \\
\text { (mmol/L) }\end{array}$ & $99.7 \pm 2.5$ & $100.1 \pm 2.3$ & $100.0 \pm 2.6$ & $99.1 \pm 2.6$ & 0.148 \\
\hline $\begin{array}{l}\text { Bicarbonate } \\
\text { (mmol/L) }\end{array}$ & $24.0 \pm 2.5$ & $24.1 \pm 2.5$ & $23.7 \pm 2.3$ & $24.1 \pm 2.6$ & 0.770 \\
\hline $\operatorname{ALT}(\mathrm{U} / \mathrm{L})$ & $20.4 \pm 12.5$ & $20.5 \pm 12.1$ & $23.0 \pm 18.4$ & $18.8 \pm 8.0$ & 0.460 \\
\hline Alk-P (mg/dL) & $113.9 \pm 61.5$ & $117.3 \pm 79.3$ & $103.0 \pm 42.4$ & $117.1 \pm 54.2$ & 0.578 \\
\hline $\begin{array}{l}\text { Fasting glucose } \\
(\mathrm{mg} / \mathrm{dL})\end{array}$ & $139.7 \pm 66.6$ & $143.3 \pm 57.0$ & $140.2 \pm 75.8$ & $136.4 \pm 69.6$ & 0.890 \\
\hline $\mathrm{HbA}_{1 c}(\%)$ & $6.2 \pm 1.5$ & $6.0 \pm 1.1$ & $6.0 \pm 1.6$ & $6.3 \pm 1.8$ & 0.573 \\
\hline $\begin{array}{l}\text { WBC count (1000 } \\
\text { per cumm) }\end{array}$ & $6.3 \pm 1.8$ & $6.2 \pm 1.6$ & $6.4 \pm 1.6$ & $6.5 \pm 2.0$ & 0.741 \\
\hline $\begin{array}{l}\text { Hemoglobin } \\
(\mathrm{g} / \mathrm{dL})\end{array}$ & $10.1 \pm 1.3$ & $9.7 \pm 1.0$ & $10.2 \pm 1.6$ & $10.3 \pm 1.4$ & 0.077 \\
\hline $\begin{array}{l}\text { High-sensitive } \\
\text { CRP (mg/dL) }\end{array}$ & $0.514 \pm 0.706$ & $0.573 \pm 0.662$ & $0.343 \pm 0.305$ & $0.562 \pm 0.875$ & 0.357 \\
\hline Ferritin (ng/mL) & $510.3 \pm 570.7$ & $508.5 \pm 541.1$ & $595.1 \pm 944.2$ & $464.9 \pm 229.4$ & 0.723 \\
\hline
\end{tabular}


Table 1 Demographic characteristics of the study population (Continued)

\begin{tabular}{|c|c|c|c|c|c|}
\hline $\begin{array}{l}\text { Transferrin } \\
\text { saturation (\%) }\end{array}$ & $26.3 \pm 11.7$ & $24.8 \pm 10.8$ & $29.9 \pm 15.7$ & $25.4 \pm 9.5$ & 0.178 \\
\hline \multicolumn{6}{|l|}{$\begin{array}{l}\text { Peridialytic blood } \\
\text { pressure }\end{array}$} \\
\hline $\begin{array}{l}\text { predialytic SBP } \\
(\mathrm{mmHg})\end{array}$ & $143.1 \pm 15.5$ & $138.1 \pm 16.6$ & $141.5 \pm 13.8$ & $147.9 \pm 14.3$ & $0.009^{*}$ \\
\hline $\begin{array}{l}\text { postdialytic SBP } \\
(\mathrm{mmHg})\end{array}$ & $143.1 \pm 17.1$ & $152.6 \pm 19.2$ & $142.7 \pm 14.5$ & $135.7 \pm 12.6$ & $<0.001^{*}$ \\
\hline $\begin{array}{l}\text { predialytic DBP } \\
(\mathrm{mmHg})\end{array}$ & $78.2 \pm 6.8$ & $74.9 \pm 6.9$ & $77.9 \pm 5.8$ & $81 . .0 \pm 6.1$ & $<0.001^{*}$ \\
\hline $\begin{array}{l}\text { postdialytic DBP } \\
(\mathrm{mmHg})\end{array}$ & $79.1 \pm 6.2$ & $80.0 \pm 6.8$ & $79.6 \pm 6.6$ & $78.2 \pm 5.4$ & 0.345 \\
\hline $\begin{array}{l}\text { predialytic MAP } \\
(\mathrm{mmHg})\end{array}$ & $99.8 \pm 9.1$ & $96.0 \pm 9.6$ & $99.1 \pm 7.7$ & $103.3 \pm 8.1$ & $0.001^{*}$ \\
\hline $\begin{array}{l}\text { postdialytic MAP } \\
(\mathrm{mmHg})\end{array}$ & $100.5 \pm 9.0$ & $104.2 \pm 10.1$ & $100.6 \pm 8.4$ & $97.3 \pm 7.2$ & $0.001^{*}$ \\
\hline $\begin{array}{l}\text { predialytic PP } \\
(\mathrm{mmHg})\end{array}$ & $64.9 \pm 11.4$ & $63.2 \pm 11.8$ & $63.6 \pm 11.1$ & $67.0 \pm 11.1$ & 0.238 \\
\hline $\begin{array}{l}\text { Postdialytic PP } \\
(\mathrm{mmHg})\end{array}$ & $64.0 \pm 13.8$ & $72.6 \pm 15.2$ & $63.2 \pm 11.4$ & $57.5 \pm 9.8$ & $<0.001^{*}$ \\
\hline $\begin{array}{l}\text { Ultrafiltration volume } \\
(\mathrm{Kg})\end{array}$ & $2.4 \pm 0.8$ & $2.1 \pm 0.5$ & $2.3 \pm 0.9$ & $2.6 \pm 0.8$ & $0.006^{*}$ \\
\hline CT ratio > 50\% (\%) & 68.7 & 89.7 & 63.0 & 55.1 & $0.002^{*}$ \\
\hline
\end{tabular}

Values are expressed as mean \pm SD or percent unless otherwise listed. Abbreviations: ACE, angiotensin converting enzyme; ARB, angiotensin II-receptor blocker; ALT, alanine aminotransferase; Alk-P, alkaline phosphatase; HbA1c, glycosylated hemoglobin; WBC, white blood cell; CRP, C-reactive protein; SBP, systolic blood pressure; DBP, diastolic blood pressure; MAP, mean arterial pressure; PP, pulse pressure; CT, cardiothoracic. ${ }^{*}: p<0.05$.

-5 to $5 \mathrm{mmHg}$ ( $p=0.030$; log-rank test) and for those with an average postdialysis SBP drop of more than 5 $\mathrm{mmHg}(p=0.016$; log-rank test) (Figure 3$)$. In addition, patients with an average postdialysis SBP rise of more

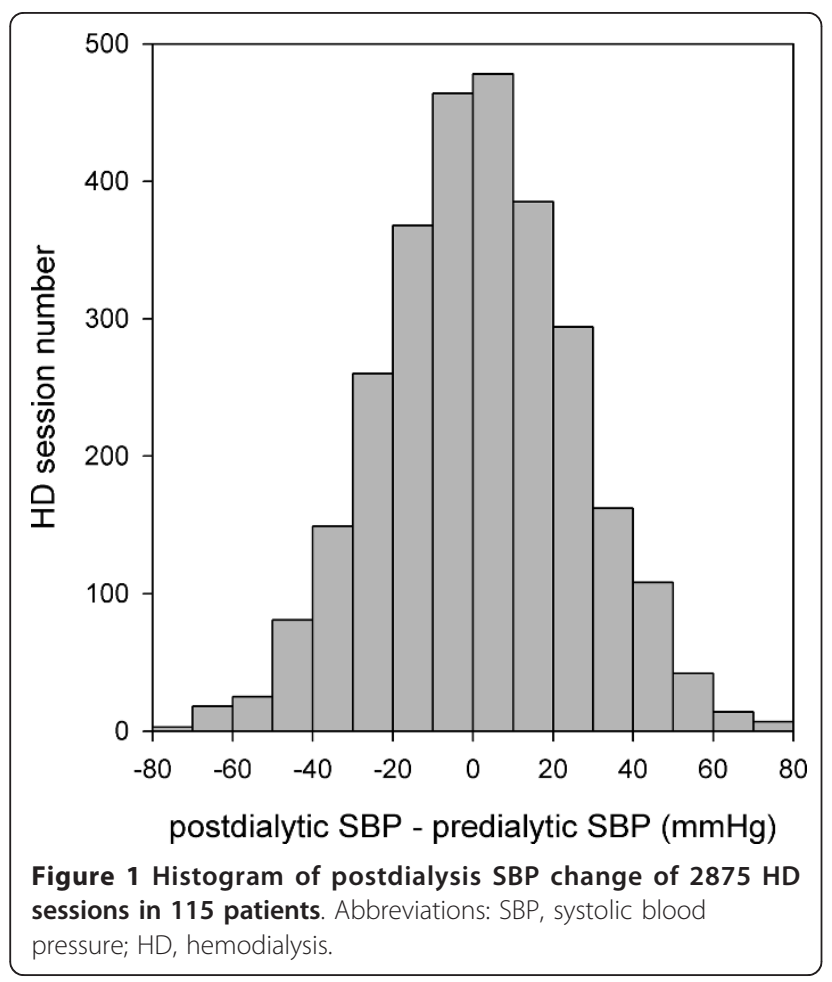

than $5 \mathrm{mmHg}$ had a significantly higher all-cause mortality rate than those with an average postdialysis SBP change between -5 to $5 \mathrm{mmHg}(p=0.049$; log-rank test) and those with an average postdialysis SBP drop of more than $5 \mathrm{mmHg}$ ( $p=0.011$; log-rank test) (Figure 4 ).

\section{Significant predictors of all-cause mortality by multivariate Cox regression analysis}

As shown in Table 2, initial univariate Cox regression analysis of variables significantly associated with allcause mortality $(p<0.10)$ indicated that old age, male gender, low $\mathrm{Kt} / \mathrm{V}$, diabetes mellitus, cardiovascular disease, underlying malignancy, hypoalbuminemia, high fasting blood glucose, elevated high-sensitive C-reactive protein (CRP), average postdialysis SBP rise of more than $5 \mathrm{mmHg}$, large ultrafiltration volume, and high CT ratio increased the risk. We included all these variables in a multivariate Cox regression analysis. The result indicated that old age, male gender, hypoalbuminemia, elevated baseline high-sensitive CRP, large ultrafiltration volume, high CT ratio, and average postdialysis SBP rise of more than $5 \mathrm{mmHg}$ were independent predictors of 4-year all-cause mortality.

\section{Positive correlation between postdialysis SBP rise and high $\mathrm{CT}$ ratio}

As shown in Table 1, among patients with an average postdialysis SBP rise of more than $5 \mathrm{mmHg}$, up to 
89.7\% suffered from a high CT ratio (more than 50\%). This showed that patients with an average postdialysis SBP rise might be associated with subclinical volume overload, and/or might suffer from cardiomyopathy. We found a significant positive correlation between postdialysis SBP rise and high CT ratio $(r=0.247, p=0.008)$ (Figure 5). However, there were still some patients with a decline in SBP during HD had a high CT ratio. This is consistent with the above findings of multivariate analysis that both postdialysis SBP rise and high CT ratio are independent outcome predictors.

\section{Discussion}

In chronic HD patients, there are three different time periods for BP recordings: peridialysis, intradialysis, and interdialysis [19]. The optimal BP of chronic HD patients recommended by the KDOQI guidelines is based on peridialysis $\mathrm{BP}$, rather than intradialytic or interdialysis BP [12]. Previous studies have shown a reverse epidemiology association between absolute predialysis and postdialysis $\mathrm{BP}$ values and clinical outcomes $[18,20]$. In the present study, we examined the relationship between peridialysis BP alterations and outcomes, which revealed that patients with an average postdialysis SBP rise of more than $5 \mathrm{mmHg}$ were more likely to suffer from 4-year cardiovascular and all-cause mortality. A higher CT ratio was also an independent long-term outcome predictor in our study. This is consistent with previous studies which showed that a $\mathrm{CT}$ ratio of more than $50 \%$ was associated with 2 -year mortality in chronic HD patients [21,22]. Meanwhile, we found that among patients with an average postdialysis SBP rise of more than $5 \mathrm{mmHg}$, up to $89.7 \%$ suffered from a high CT ratio. This suggests that the prevalence of subclinical fluid overload is high in chronic HD patients, and that volume excess may manifest as postdialysis hypertension. Furthermore, previous outcome studies showing that intradialytic hypertension was associated with 2year all-cause mortality did not examined cardiovascular outcomes $[1,4]$. To the best of our knowledge, our study is the first to demonstrate the positive correlation between postdialysis SBP rises and long-term cardiovascular mortality.

Our data also showed that among patients with postdialysis SBP rise, their MAP, DBP, and PP also rose (Figure 2). However, after multivariate Cox regression analysis, only SBP remained significant in predicting outcomes. Patients with an average postdialysis SBP rise of more than $5 \mathrm{mmHg}$ carried a 2.9 times increased risk for all-cause mortality than those without. Our results are in accordance with a study conducted by Inrig et al., which reported that an increase in SBP of more than 10 mmHg during HD was associated with decreased 2-year overall survival but was limited to patients with predialysis SBP $<120 \mathrm{mmHg}$. Although their study was conducted in a larger cohort of 1748 incident HD patients, the baseline BP measurements were averaged from only 3 consecutive HD sessions [1]. In contrast, our results were derived from the mean values of SBP recorded for 2 months. When plotting a histogram of postdialysis SBP change for each patient, the histogram derived from more times of HD sessions $(n=25)$ should more closely resemble a normal distribution. Therefore, patient grouping might be different while average postdialysis BP change was derived from different numbers of HD times. Moreover, the averaged predialysis SBP of the majority of our patients were more than $120 \mathrm{mmHg}$, which might also explain why we did not find such predictive value when categorizing our patients by $10-$ mmHg threshold.

Previous studies have shown that BP measured at the 44-hour interdialysis period, including ambulatory BP monitoring and self-measurement by the patient using home BP monitoring, correlates well with left

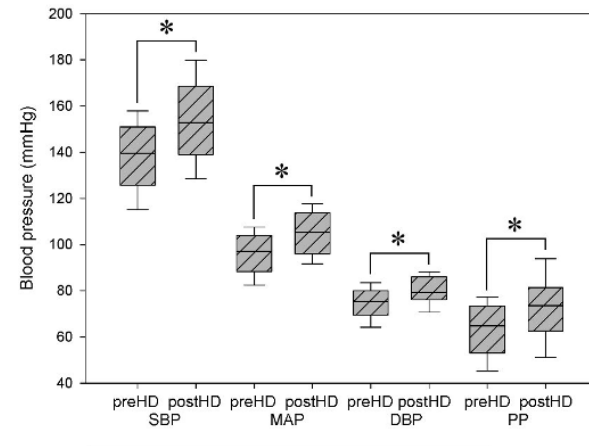

(A) $\square$ Patients with postdialytic SBP rise $>5 \mathrm{mmHg}(n=39)$

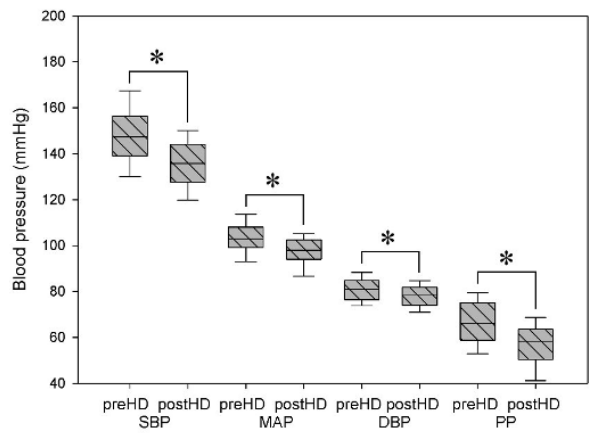

(B) $\square$ Patients with postdialylic SBP drop $>5 \mathrm{mmHg}(n=49)$

Figure 2 Predialysis and postdialysis blood pressure categorized by postdialysis SBP rise $>5 \mathrm{mmHg}(n=39)(\mathrm{A})$ and those with postdialysis SBP drop $>5 \mathrm{mmHg}(n=49)(B)$. Abbreviations: HD, hemodialysis; SBP, systolic blood pressure; MAP, mean arterial pressure; DBP, diastolic blood pressure; PP, pulse pressure. (*: $p<0.001)$. 


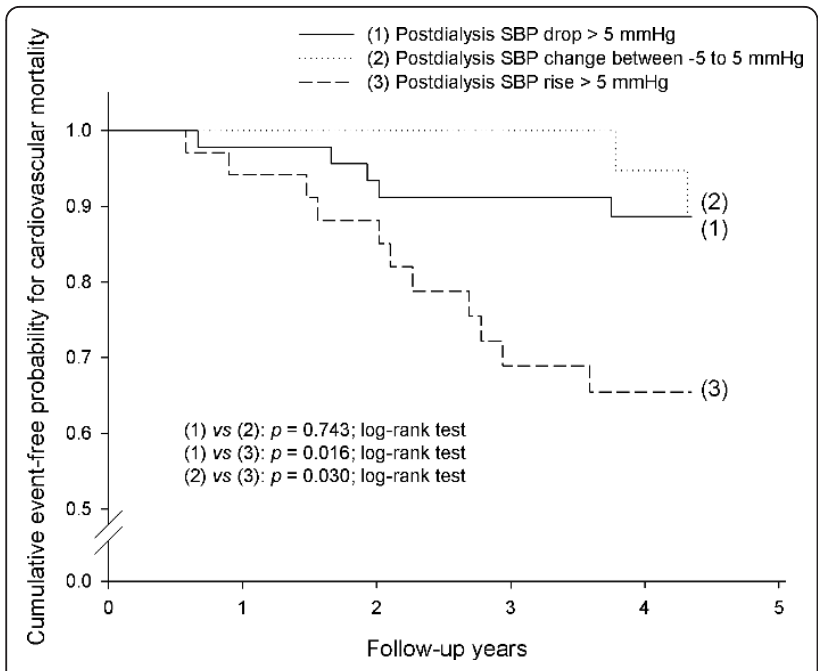

Figure 3 Hemodialysis patients with an average postdialysis systolic blood pressure (SBP) rise of more than $5 \mathrm{mmHg}$ were at the highest risk of cardiovascular mortality, as compared to those with an average postdialysis SBP change between -5 to $5 \mathrm{mmHg}(p=0.030$; log-rank test) and those with an average postdialysis SBP drop $>5 \mathrm{mmHg}(p=0.016$; log-rank test).

ventricular hypertrophy and is a predictor of cardiovascular and all-cause mortality $[14,16]$. Although interdialysis ambulatory BP measurement is of greater prognostic value than $\mathrm{HD}$ unit $\mathrm{BP}$ recordings, it requires equipment and is not readily available in most HD units [19]. In addition, accurate self-measurement by the patient using home BP monitoring during the interdialysis period may be difficult for elderly and frail patients.

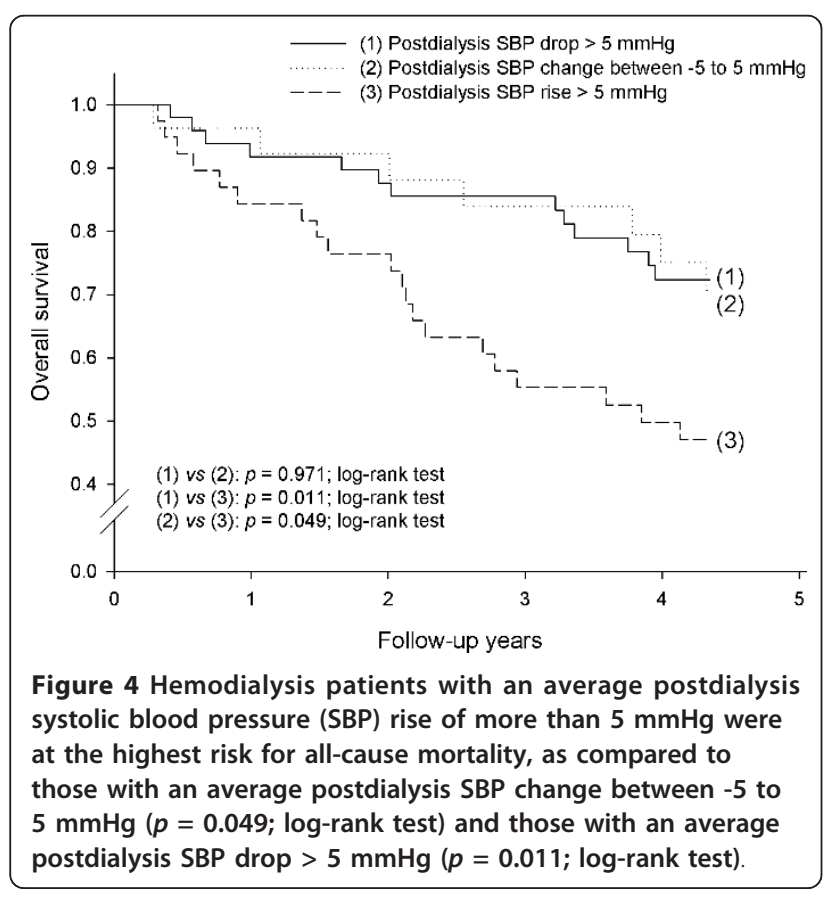

On the other hand, peridialysis BP measurements, which are performed by dialysis unit staff shortly before and after the HD session, are much easily assessible. Furthermore, Van Buren et al. recently unveiled the linkage between intradialytic hypertension and interdialytic ambulatory BP burden. Their findings explain the increased morbidity and mortality seen in patients with intradialytic hypertension [23].

Although peridialysis BP recorded from 3-6 HD sessions have been reported to be poorly correlated with end-organ damage and cardiovascular outcomes [14-16], the discrepancy was suggested to result from the highly variable nature of peridialysis BP levels $[19,24,25]$. We believe that a high variability of peridialysis BP recordings can be offset by increasing the number of recording times. In addition, a previous study also showed that average predialysis systolic BP taken more than 1 month may be equally representative of the true BP than 24hour ambulatory BP monitoring [17]. Therefore, we suggest that peridialysis BP averaged from 25 consecutive HD sessions is more reproducible and practical to reflect the actual postdialysis $\mathrm{BP}$ alterations in chronic HD patients. On the other hand, categorizing patients by a $5-\mathrm{mmHg}$ interval which was averaged from a 2month BP data might hinder its clinical applicability. Furthermore, it should be emphasized that a rise in postdialysis SBP can not be concluded from one single HD session BP recording.

There are emerging data showing that postdialysis hypertension is associated with poor outcomes, but the mechanisms of such poor outcomes remain poorly understood $[1,26]$. Our results revealed that postdialysis SBP rise was associated with fluid overload, as evidenced by a higher CT ratio, lower ultrafiltration volume, and lower hemoglobin level. Therefore, postdialysis SBP rise may be an implication of volume excess. In patients suffering from postdialysis hypertension, clinicians should prudently assess their volume status and intensify fluid removal as needed. Nevertheless, since both postdialysis SBP rise and high CT ratio were independent outcome predictors, there must be a mechanism other than volume excess contributing to postdialysis hypertension, such as elevated circulating endothelin and intradialytic sodium load. Therefore, drugs that inhibit the reninangiotensin system, such as angiotensin converting enzyme (ACE) inhibitors or angiotensin II-receptor blockers (ARB) should be preferred because they cause greater regression of $\mathrm{LVH}$, reduce sympathetic nerve activity, reduce pulse wave velocity, may improve endothelial function, and may reduce oxidative stress [12].

Our multivariate analysis also revealed that high UF volume had an independent association with mortality, which was consistent with previous studies showing the 
Table 2 Univariate and multivariate Cox regression analysis of significant predictors of 4-year all-cause mortality in hemodialysis patients

\begin{tabular}{|c|c|c|c|c|c|c|c|c|}
\hline \multirow[t]{3}{*}{ Factor } & \multicolumn{4}{|c|}{ Univariate } & \multicolumn{4}{|c|}{ Multivariate } \\
\hline & \multirow[t]{2}{*}{ HR } & \multicolumn{2}{|c|}{$95 \% \mathrm{Cl}$} & \multirow[t]{2}{*}{$p$ Value } & \multirow[t]{2}{*}{ HR } & \multicolumn{2}{|c|}{$95 \% \mathrm{Cl}$} & \multirow[t]{2}{*}{$p$ Value } \\
\hline & & Lower & Upper & & & Lower & Upper & \\
\hline Age (10 year) & 1.713 & 1.284 & 2.286 & $<0.001^{*}$ & 1.947 & 1.366 & 2.775 & $<0.001$ \\
\hline Male gender (\%) & 1.899 & 1.014 & 3.557 & $0.045^{*}$ & 4.267 & 1.985 & 9.171 & $<0.001$ \\
\hline Dialysis duration (year) & 0.951 & 0.889 & 1.017 & 0.140 & & & & \\
\hline Body mass index $\left(\mathrm{Kg} / \mathrm{m}^{2}\right)$ & 1.000 & 0.914 & 1.093 & 0.995 & & & & \\
\hline Smoking index & 1.167 & 0.795 & 1.712 & 0.430 & & & & \\
\hline $\mathrm{Kt} / \mathrm{N}$ & 0.116 & 0.033 & 0.416 & $0.001^{*}$ & & & & \\
\hline \multicolumn{9}{|l|}{ Comorbidities (\%) } \\
\hline Diabetes mellitus (\%) & 2.125 & 1.138 & 3.967 & $0.018^{*}$ & & & & \\
\hline Hypertension (\%) & 1.352 & 0.417 & 4.388 & 0.615 & & & & \\
\hline Cardiovascular disease (\%) & 2.256 & 1.204 & 4.227 & $0.011^{*}$ & & & & \\
\hline Prior stroke (\%) & 2.588 & 0.797 & 8.406 & 0.114 & & & & \\
\hline Malignancy (\%) & 2.704 & 1.130 & 6.467 & $0.025^{*}$ & & & & \\
\hline Hepatitis B infection (\%) & 0.887 & 0.273 & 2.879 & 0.842 & & & & \\
\hline Hepatitis C infection (\%) & 0.896 & 0.376 & 2.135 & 0.805 & & & & \\
\hline \multicolumn{9}{|l|}{ Medications } \\
\hline Antihypertensive agents (\%) & 0.921 & 0.439 & 1.935 & 0.829 & & & & \\
\hline ACE inhibitor/ARB (\%) & 1.141 & 0.614 & 2.121 & 0.676 & & & & \\
\hline Vitamin $\mathrm{D}_{3}(\%)$ & 1.156 & 0.533 & 2.510 & 0.713 & & & & \\
\hline \multicolumn{9}{|l|}{ Laboratory data } \\
\hline Albumin (g/dL) & 0.136 & 0.044 & 0.425 & $0.001^{*}$ & 0.032 & 0.008 & 0.126 & $<0.001$ \\
\hline Total cholesterol (mg/dL) & 0.997 & 0.989 & 1.006 & 0.509 & & & & \\
\hline Triglycerides (mg/dL) & 1.001 & 0.999 & 1.003 & 0.442 & & & & \\
\hline Sodium (mmol/L) & 0.937 & 0.841 & 1.044 & 0.236 & & & & \\
\hline Chloride $(\mathrm{mmol} / \mathrm{L})$ & 0.984 & 0.869 & 1.114 & 0.801 & & & & \\
\hline Bicarbonate $(\mathrm{mmol} / \mathrm{L})$ & 0.959 & 0.851 & 1.082 & 0.497 & & & & \\
\hline $\operatorname{ALT}(U / L)$ & 1.001 & 0.978 & 1.024 & 0.963 & & & & \\
\hline Alk-P (mg/dL) & 1.000 & 0.995 & 1.005 & 0.927 & & & & \\
\hline Fasting glucose (mg/dL) & 1.004 & 1.000 & 1.008 & $0.030^{*}$ & & & & \\
\hline $\mathrm{HbA}_{1 \mathrm{c}}(\%)$ & 1.135 & 0.956 & 1.347 & 0.149 & & & & \\
\hline WBC count (1000 per cumm) & 0.958 & 0.788 & 1.166 & 0.671 & & & & \\
\hline Hemoglobin $(\mathrm{g} / \mathrm{dL})$ & 1.019 & 0.806 & 1.289 & 0.873 & & & & \\
\hline High-sensitive CRP (mg/dL) & 1.432 & 1.062 & 1.932 & $0.019^{*}$ & 1.534 & 1.072 & 2.195 & 0.019 \\
\hline Ferritin $(\mathrm{ng} / \mathrm{mL})$ & 1.000 & 1.000 & 1.001 & 0.743 & & & & \\
\hline Transferrin saturation (\%) & 0.826 & 0.065 & 10.479 & 0.883 & & & & \\
\hline \multicolumn{9}{|l|}{ Peridialytic BP } \\
\hline predialytic SBP (mmHg) & 1.000 & 0.980 & 1.020 & 0.993 & & & & \\
\hline postdialytic SBP (mmHg) & 1.008 & 0.990 & 1.026 & 0.393 & & & & \\
\hline predialytic MAP (mmHg) & 0.992 & 0.959 & 1.027 & 0.648 & & & & \\
\hline postdialytic MAP (mmHg) & 1.003 & 0.970 & 1.038 & 0.844 & & & & \\
\hline predialytic DBP (mmHg) & 0.978 & 0.934 & 1.024 & 0.346 & & & & \\
\hline postdialytic DBP $(\mathrm{mmHg})$ & 0.981 & 0.932 & 1.032 & 0.452 & & & & \\
\hline predialytic PP (mmHg) & 1.008 & 0.981 & 1.035 & 0.578 & & & & \\
\hline postdialytic PP (mmHg) & 1.016 & 0.994 & 1.038 & 0.159 & & & & \\
\hline \multicolumn{9}{|l|}{ Peridialytic BP alterations (no as reference) } \\
\hline postdialytic SBP rise $>5$ mmHg (yes/no) & 2.382 & 1.280 & 4.434 & $0.006^{*}$ & 3.925 & 1.420 & 10.846 & 0.008 \\
\hline postdialytic MAP rise $>5$ mmHg (yes/no) & 1.762 & 0.929 & 3.344 & 0.083 & & & & \\
\hline postdialytic DBP rise $>5$ mmHg (yes/no) & 1.602 & 0.800 & 3.207 & 0.184 & & & & \\
\hline postdialytic PP rise $>5$ mmHg (yes/no) & 1.548 & 0.808 & 2.965 & 0.188 & & & & \\
\hline
\end{tabular}


Table 2 Univariate and multivariate Cox regression analysis of significant predictors of 4-year all-cause mortality in hemodialysis patients (Continued)

\begin{tabular}{|c|c|c|c|c|c|c|c|c|}
\hline Ultrafiltration volume (Kg) & 1.355 & 0.944 & 1.944 & $0.099^{*}$ & 3.470 & 2.045 & 5.889 & $<0.001$ \\
\hline CT ratio > 50\% (yes/no) & 8.960 & 2.322 & 34.572 & $0.001^{*}$ & 7.560 & 2.048 & 27.912 & 0.002 \\
\hline
\end{tabular}

Abbreviations: $\mathrm{HR}$, Hazard ratio; $\mathrm{Cl}$, confidence interval; $\mathrm{ACE}$, angiotensin converting enzyme; $\mathrm{ARB}$, angiotensin II-receptor blocker; $\mathrm{ALT}$, alanine aminotransferase; Alk-P, alkaline phosphatase; HbA1c, glycosylated hemoglobin; WBC, white blood cell; CRP, C-reactive protein; BP, blood pressure; SBP, systolic blood pressure; $\mathrm{MAP}$, mean arterial pressure; $\mathrm{DBP}$, diastolic blood pressure; $\mathrm{PP}$, pulse pressure; $\mathrm{CT}$, cardiothoracic. *Variables further included in the multivariate Cox regression analysis.

mortality predictive value of increased interdialytic weight gain $[27,28]$. However, we found patients with postdialysis SBP rise had the lowest UF volume. As mentioned above, this patient group may be volume overloaded. It seems possible that volume excess in this patient group was caused by low UF volume. However, such interpretation was limited by the lack of assessment of patient dry weight in our study. The present data suggest that both high UF volume and postdialysis SBP rise were both independent outcome predictors.

There are some limitations to our study. First, we did not include intradialytic BP in our study. However, a postdialysis $\mathrm{BP}$ rise may be derived from intradialytic BP elevation. Second, the sample size of our cohort is relatively small, but the BP values were averaged from 25 consecutive HD sessions during a 2-month period. Third, the positive correlation between postdialysis SBP rise and volume excess is cross-sectional rather than longitudinal. Fourth, because of the non-randomized nature of our study design, there is an excess of malignancy in the patient group with a SBP rise. Nevertheless, the independent predictive value of postdialysis SBP rise was evidenced by the multivariate analysis. Finally, the event rate was not optimal for multivariate regression analysis because of the relatively small patient number in the present study. Therefore, further large scale longitudinal studies are

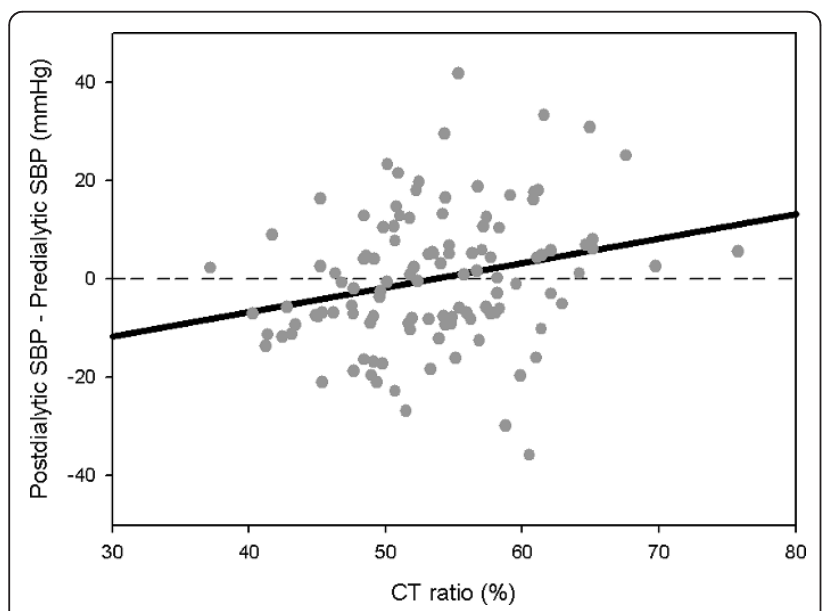

Figure 5 Scatter plot showing the positive correlation between postdialysis SBP alterations and CT ratio $(r=0.247, p=0.008)$ Abbreviations: SBP, systolic blood pressure; $C T$, cardiothoracic. needed to investigate the impact of volume reduction on postdialysis SBP alterations and patient outcomes.

\section{Conclusions}

The findings of the present study indicated that a rise in postdialysis SBP in chronic HD patients was associated with a higher risk of both long-term cardiovascular and all-cause mortality throughout the 4 years of follow-up. Since postdialysis BP rise might reflect subclinical volume excess, we suggest intensive evaluation of volume status in such patients in order to improve their survival. In addition, future studies are warranted to examine benefits of optimizing ACE inhibitor or ARB use in patients with postdialysis SBP rises.

\section{Acknowledgements}

This study was supported by a grant from Taipei Veterans General Hospital, Taipei, Taiwan (VGH96A-529). The authors thank physicians and nurses of the HD unit for technical assistance.

\section{Author details}

'Division of Nephrology, Department of Medicine, Taipei Veterans General Hospital, No. 201, Section 2, Shih-Pai Road, Taipei 11217, Taiwan. ${ }^{2}$ School of Medicine, National Yang-Ming University, Taipei, Taiwan.

\section{Authors' contributions}

$C Y, W Y$, and $Y L$ designed research; $C Y$ performed research; $C Y$ and $Y L$ analyzed data; and CY and YL wrote the paper. All authors read and approved the final manuscript.

\section{Competing interests}

The authors declare that they have no competing interests.

Received: 23 August 2011 Accepted: 14 March 2012

Published: 14 March 2012

\section{References}

1. Inrig JK, Patel UD, Toto RD, Szczech LA: Association of blood pressure increases during hemodialysis with 2-year mortality in incident hemodialysis patients: a secondary analysis of the Dialysis Morbidity and Mortality Wave 2 Study. Am J Kidney Dis 2009, 54:881-890.

2. Cirit M, Akcicek F, Terzioglu E, Soydas C, Ok E, Ozbasli CF, et al: 'Paradoxical' rise in blood pressure during ultrafiltration in dialysis patients. Nephrol Dial Transplant 1995, 10:1417-1420.

3. Locatelli F, Cavalli A, Tucci B: The growing problem of intradialytic hypertension. Nat Rev Nephrol 2010, 6:41-48.

4. Inrig JK, Oddone EZ, Hasselblad V, Gillespie B, Patel UD, Reddan D, et al: Association of intradialytic blood pressure changes with hospitalization and mortality rates in prevalent ESRD patients. Kidney Int 2007, 71:454-461.

5. Chou KJ, Lee PT, Chen CL, Chiou CW, Hsu CY, Chung HM, et al: Physiological changes during hemodialysis in patients with intradialysis hypertension. Kidney Int 2006, 69:1833-1838. 
6. Inrig JK: Intradialytic hypertension: a less-recognized cardiovascular complication of hemodialysis. Am J Kidney Dis 2010, 55:580-589.

7. Gunal Al, Karaca I, Celiker H, Ilkay E, Duman S: Paradoxical rise in blood pressure during ultrafiltration is caused by increased cardiac output. J Nephrol 2002, 15:42-47.

8. Chen J, Gul A, Sarnak MJ: Management of intradialytic hypertension: the ongoing challenge. Semin Dial 2006, 19:141-145.

9. Inrig JK, Van BP, Kim C, Vongpatanasin W, Povsic TJ, Toto RD: Intradialytic hypertension and its association with endothelial cell dysfunction. Clin 」 Am Soc Nephrol 2011, 6:2016-2024.

10. Causes of death. USRDS. United States Renal Data System. Am J Kidney Dis 1997, 30:S107-S117.

11. Foley RN, Parfrey PS, Harnett JD, Kent GM, Murray DC, Barre PE: Impact of hypertension on cardiomyopathy, morbidity and mortality in end-stage renal disease. Kidney Int 1996, 49:1379-1385.

12. $\mathrm{K} / \mathrm{DOQ}$ clinical practice guidelines for cardiovascular disease in dialysis patients. Am J Kidney Dis 2005, 45:S1-153.

13. Chazot C, Jean G: Intradialytic hypertension: it is time to act. Nephron Clin Pract 2010, 115:c182-c188.

14. Agarwal R, Brim NJ, Mahenthiran J, Andersen MJ, Saha C: Out-ofhemodialysis-unit blood pressure is a superior determinant of left ventricular hypertrophy. Hypertension 2006, 47:62-68.

15. Agarwal R, Peixoto AJ, Santos SF, Zoccali C: Pre- and postdialysis blood pressures are imprecise estimates of interdialytic ambulatory blood pressure. Clin J Am Soc Nephrol 2006, 1:389-398.

16. Alborzi P, Patel N, Agarwal R: Home blood pressures are of greater prognostic value than hemodialysis unit recordings. Clin J Am Soc Nephrol 2007, 2:1228-1234.

17. Zoccali C, Mallamaci F, Tripepi G: Hypertension as a cardiovascular risk factor in end-stage renal failure. Curr Hypertens Rep 2002, 4:381-386.

18. Zager PG, Nikolic J, Brown RH, Campbell MA, Hunt WC, Peterson D, et al: " $\mathrm{U}$ " curve association of blood pressure and mortality in hemodialysis patients. Medical Directors of Dialysis Clinic, Inc. Kidney Int 1998, 54:561-569.

19. Sinha AD, Agarwal R: Peridialytic, intradialytic, and interdialytic blood pressure measurement in hemodialysis patients. Am J Kidney Dis 2009, 54:788-791.

20. Port FK, Hulbert-Shearon TE, Wolfe RA, Bloembergen WE, Golper TA Agodoa LY, et al: Predialysis blood pressure and mortality risk in a national sample of maintenance hemodialysis patients. Am J Kidney Dis 1999, 33:507-517.

21. Chen KH, Lin-Tan DT, Huang WH, Hung CC, Chang CT, Huang JY, et al. Cardiothoracic ratio, malnutrition, inflammation, and two-year mortality in non-diabetic patients on maintenance hemodialysis. Kidney Blood Press Res 2008, 31:143-151.

22. Yen TH, Lin JL, Lin-Tan DT, Hsu KH: Cardiothoracic ratio, inflammation, malnutrition, and mortality in diabetes patients on maintenance hemodialysis. Am J Med Sci 2009, 337:421-428.

23. Van Buren PN, Kim C, Toto R, Inrig JK: Intradialytic hypertension and the association with interdialytic ambulatory blood pressure. Clin J Am SoC Nephrol 2011, 6:1684-1691.

24. Rohrscheib MR, Myers OB, Servilla KS, Adams CD, Miskulin D, Bedrick EJ, et al: Age-related blood pressure patterns and blood pressure variability among hemodialysis patients. Clin J Am Soc Nephrol 2008, 3:1407-1414.

25. Agarwal R, Andersen MJ, Bishu K, Saha C: Home blood pressure monitoring improves the diagnosis of hypertension in hemodialysis patients. Kidney Int 2006, 69:900-906.

26. Agarwal R, Light RP: Intradialytic hypertension is a marker of volume excess. Nephrol Dial Transplant 2010, 25:3355-3361.

27. Szczech LA, Reddan DN, Klassen PS, Coladonato J, Chua B, Lowrie EG, et al: Interactions between dialysis-related volume exposures, nutritional surrogates and mortality among ESRD patients. Nephrol Dial Transplant 2003, 18:1585-1591.

28. Foley RN, Herzog CA, Collins AJ: Blood pressure and long-term mortality in United States hemodialysis patients: USRDS Waves 3 and 4 Study. Kidney Int 2002, 62:1784-1790.

Pre-publication history

The pre-publication history for this paper can be accessed here:

http //www biomedcentral.com/1471-2369/13/12/prepub doi:10.1186/1471-2369-13-12

Cite this article as: Yang et al:: Postdialysis blood pressure rise predicts long-term outcomes in chronic hemodialysis patients: a four-year prospective observational cohort study. BMC Nephrology 2012 13:12.

\section{Submit your next manuscript to BioMed Central and take full advantage of:}

- Convenient online submission

- Thorough peer review

- No space constraints or color figure charges

- Immediate publication on acceptance

- Inclusion in PubMed, CAS, Scopus and Google Scholar

- Research which is freely available for redistribution

Submit your manuscript at www.biomedcentral.com/submit
C Biomed Central 